\title{
Concept and Viability of High Temperature Superconductor Fault Current Limiter for Power Systems Protection
}

\author{
Engr Dr Damian Obioma Dike ${ }^{1}$ Okwe Gerald Ibe ${ }^{2}$, Inyama Kelechi ${ }^{2}$, \\ Olekaibe Richard ${ }^{2}$ \\ 1. Senior lecturer, Department of Electrical/Electronic Engineering Federal University of Technology \\ Owerri Imo State (Nigeria) \\ 2. Student Department of Electrical/Electronic Engineering Federal University of Technology Owerri \\ Imo State (Nigeria)
}

\begin{abstract}
In today's technological era, electrical energy is one of the most vital forms of energy and is needed directly or indirectly in almost every field. As load gradually increases on a particular power system network, a higher operating current state leading to increased fault current level is attained. It is not possible to change the rating of the equipment and devices in the system or circuits to accommodate the increasing fault currents. Integration of High Temperature Superconductor Fault Current Limiter (HTSFCL) in power system network will provide instantaneous (sub cycle) current limitation abilities, which mitigates the effects and the buildup of fault currents in the power system network. The devices in electronic and electrical circuits are sensitive to disturbance and any disturbance or fault may damage the device permanently so that it must be replaced. The cost of equipment like circuit breakers and transformers in power grid are very expensive. Moreover, replacing damaged equipment is a time and labour consuming process, which also affects the reliability of power systems. It is not possible to completely eliminate the faults but it is possible to limit the current during fault in order to save the equipment and devices in the circuits or systems. One of the solutions to this age longed problem is the application of a current limiting device in the system. This paper is centered on the concepts and viability of High Temperature fault current limiters for power systems protection. The demonstration of this High Temperature Superconductor Fault Current Limiter (HTSFCL) in power systems has been explained and simulated using MATLAB tool. The results of the simulation with and without the fault are shown
\end{abstract}

Keywords: Super conducting fault limiter, MATLAB simulation, system reliability

Accepted Date: 05 Feb 2013

\section{Introduction}

In today's world, electrical energy is unquestionably the most versatile and universally useful form of energy available. Electricity is only one of the many forms of energy used in industry, homes, businesses, and transportation. With increase in the industry, consumption of electrical energy has increased. As such, our lifestyles depend upon a reliable supply of electricity that is available whenever we need it. Because our electrical supply is fairly reliable, it is assumed that the lights will come on at the flip of a switch, that the refrigerator will keep food from spoiling, and that the air conditioner will keep homes and offices comfortable.

The electricity that we use is typically supplied via a network of transmission lines that carry the bulk of the power, and distribution lines that reach out to customer loads; like a house or industry. The majority of the distribution systems in most countries of the world operate in a radial topology in which there is a single source of power that feeds the loads connected downstream. The topology is very simple to understand and their protection schemes are well understood and work to protect loads and sources under fault conditions. However, over a period of years, loads connected on a particular distribution system keeps increasing as new neighborhoods

or small industries are added to the system. This creates a situation where the normal operating current increases, resulting in a proportional increase in the fault current levels. This may lead to frequent power outages and ultimately customer dissatisfaction if corrective actions are not taken. High Temperature Super conductor Fault Current Limiter (FCL) is a revolutionary power system device that addresses the problems due to increased fault current levels. It is a device that mitigates prospective fault currents to a lower manageable level. 


\section{Literature Survey}

Before the research and development of the fault current limiter, the main area of research was to break the circuit during fault in order to save the expensive equipment at power grids from large fault currents generated during fault. In order to handle large fault currents circuit breaker with large rating were developed. But the Problem with the circuit breakers is that they have a limited life period, and cannot break the circuit until the first current cycle goes to zero. The research and development of fault current limiters started many years ago. First the basic idea was to limit the fault current so it does not matter if the system is disconnected from supply. Many other methods were used, like air core reactors, basically it was a good approach but the only disadvantage was very high voltage drop in normal operation, for which volt-ampere reactive (VAR) compensation was required. The increase in the size of the system is the other disadvantage of this approach.

The specifications of the Fault Current Limiter and a description of the limiting behavior and the installation of the FCL are discussed in [1]. The FCL based on the Microprocessor/computer controlled method is discussed by M.M.A.Salama [2, 3]. It consists of an LC circuit tuned to minimum impedance at supply frequency and a thyristor controlled reactor as a shunt which is connected across the capacitor. The current is limited by varying the firing angle of the thyristor, due to which the circuit breaker and other protective systems can operate. The sensor and control circuits should operate accurately to detect the fault current. Fault Current Limiter reported in [4] is based on an electromagnetic circuit with iron core and adjustable air gap. Basically the impedance is much less during normal supply operation. During fault the forces produced by the fault current on the plunger causes the inductance of the device to increase, which limits the current during fault. The proper mechanical movement of the plunger is the main concern. Different approaches of limiting fault current by using PTC thermistors have been explained by Dougal [5]. The results show that the path is good enough to limit the fault current but at the same time the material characteristics need to be known in order for it to work efficiently.

\subsection{ROLE OF FAULT CURRENT LIMITER}

As mentioned earlier, the role of the FCL is to limit prospective fault current levels to a more manageable level without a significant impact on the distribution system. Consider a simple power system model, as shown in Figure 2.1, consisting of a source with voltage $V_{s}$, internal impedance $Z_{s}$, load $Z_{\text {Load }}$, and fault impedance $Z_{\text {fault }}$.
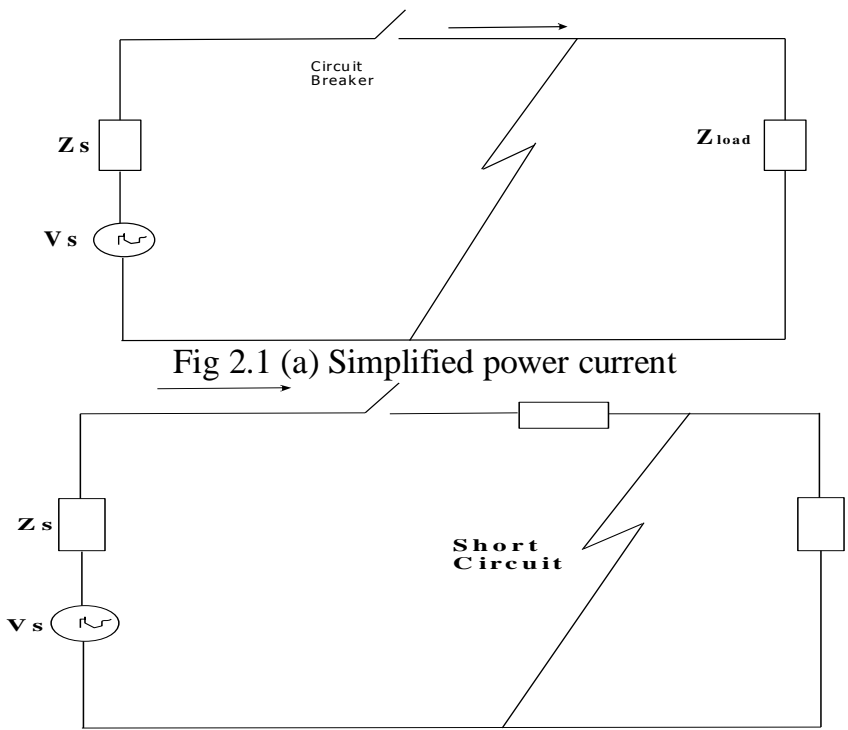

Fig 2.1 (b) modified power circuit

In Steady state

When fault occurs

$$
I_{\text {line }}=\frac{V s}{Z s+Z \text { load }} \quad-------(2.1)
$$

$$
I_{\text {fault }}=\frac{V s}{Z s+Z_{\text {fault }}} \quad-----
$$

Since the supply impedance $Z_{s}$ is much smaller than the load impedance, Equation (2.2) shows that the short circuiting of the load will substantially increase the current flow. However, if a FCL is placed in series, as shown in the modified circuit, Equation (2.3) will hold true 
Where $Z_{\text {fault }} \ll Z_{\text {load }}$

$I_{\text {fault }}=\frac{V s}{Z_{s}+Z_{f c l}+Z_{\text {fault }}}$

Equation (2.3) tells that, with an insertion of a FCL, the fault current will now be a function of not only the source $Z_{s}$ and fault impedance $Z_{\text {fault }}$, but also the impedance of the FCL. Hence, for a given source voltage and increasing $Z_{F C L}$ will decrease the fault current $I_{\text {fault }}$.

\subsection{IDEAL FAULT CURRENT LIMITER CHARACTERISTICS}

Before discussing any further, it is important that some of the ideal characteristics be laid out for an FCL. An ideal FCL should meet the following operational requirements [1, 7, 10 and 11]

1) Virtually inexistent during steady state. This implies almost zero voltage drop across the FCL itself

2) Detection of the fault current within the first cycle (less than $16.667 \mathrm{~ms}$ for $60 \mathrm{~Hz}$ and $20 \mathrm{~ms}$ for $50 \mathrm{~Hz}$ ) and reduction to a desirable percentage in the next few cycles.

3) Capable of repeated operations for multiple faults in a short period of time

4) Automatic recovery of the FCL to pre-fault state without human intervention

5) No impact on voltage and angle stability

6) Ability to work up to the distribution voltage level class

7) No impact on the normal operation of relays and circuit breakers

8) Finally, small-size device that is relatively portable, lightweight and maintenance free

\subsection{HIGH TEMPERATURE SUPERCONDUCTOR FAULT CURRENT LIMITERS (HTSFCL)}

Superconductor based fault current limiters can be configured in one of the two ways: If the superconductor is inserted in series with the circuit, then it is the resistive type. If the superconducting short circuited secondary coil is magnetically coupled to the primary winding which is placed in series with the circuit, it is known as reactive type. Here the investigation carried out is based on the computer modelling of the superconductor fault current limiter and MATLAB simulation is used for the modelling. The FCL under investigation is the resistive type. The superconducting material used is $\mathrm{Bi}-2223$. The $\mathrm{Bi}-2223$ is preferred as the superconductor material for FCL as compared to YBCO because the change in the resistivity with increase in temperature is faster in $\mathrm{Bi}-2223$. Figure 2.2 shows the variation of resistivity with the temperature, it can be seen the increase in resistivity of $\mathrm{Bi}-2223$ is faster because of increase in temperature.

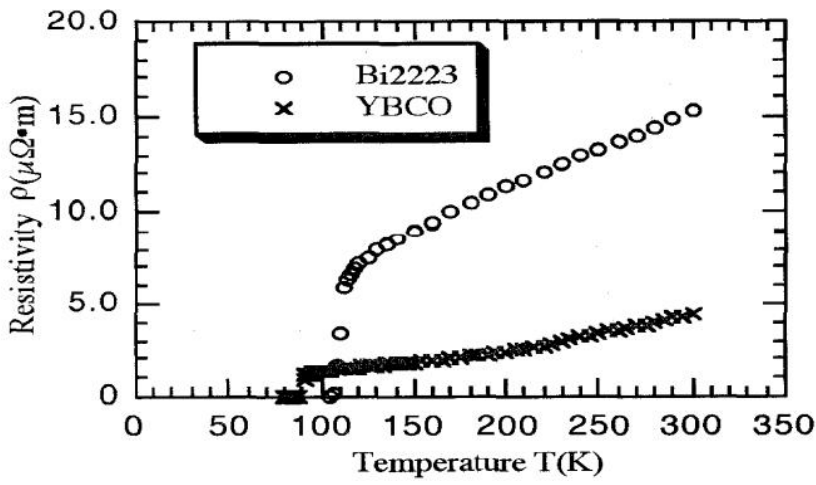

Figure 2.2 Variation of Resistivity with Temperature of Bi-2223 \& YBCO

\subsubsection{Matlab Simulation}

\section{Modelling And Implementation Of Htsfcl}

In order to predict the limiting characteristics of the HTSFCL, it is implemented in the electrical system and MATLAB simulation is carried out. By solving the differential equations the current can be obtained at any point. In the simulation we apply Runge-Kutta method to solve the differential equations using time step of $0.00001 \mathrm{~s}$. The details can be found below which lists the complete MATLAB script. The parameters that are considered are

- Thickness of the HTSFCL

- Length of the HTSFCL

- Specific heat capacity of the HTSFCL

- Specific resistance (Resistivity) of the HTSFCL

- Thermal conductivity of the HTSFCL

Figure 3.1 shows the circuit that has HTSFCL during steady state condition, where the current has nominal value of $9000^{*}$ sqrt 2 and temperature is constant at $77 \mathrm{~K}$ as superconductor is submerged in the liquid 
Nitrogen. During normal operation the switch is open and the HTSFCL is in its superconducting state. The switch is closed (short circuit) in order to observe the working of the HTSFCL during fault. During fault the HTSFCL comes out of zero resistance state and the resistance of the superconductor rises to a high value, which results in an increase of temperature.

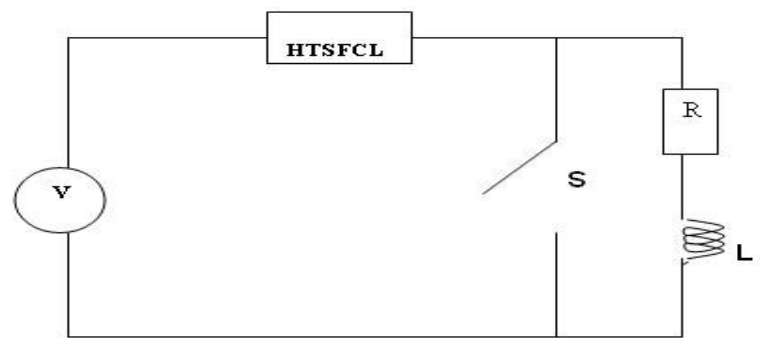

Fig3.1 Electrical Circuit with HTSFCL

Figure 3.2 shows the layout of the HTSFCL. The Superconductor layer of Bi-2223 is surrounded by stainless steel layers. The function of the stainless layers is to remove the heat from the superconductor element which helps to save the superconductor element from damage due to excess heat produced during fault.

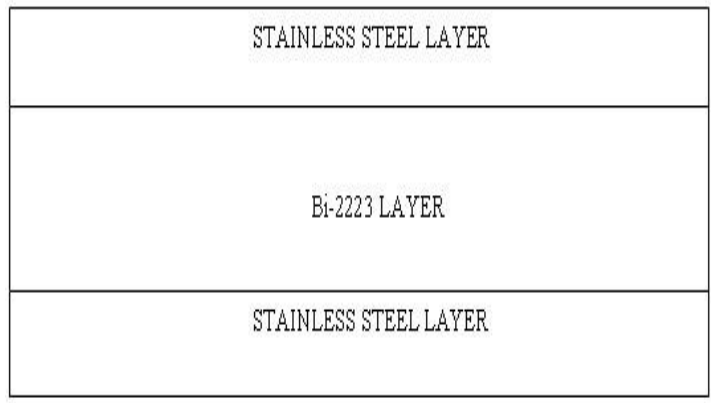

Figure 3.2 The design of the HTSFCL

format long

$\%$ Initializing variables

$\mathrm{V}=110000 * \operatorname{sqrt}(2) ; \%$ Input Supply Voltage

$\mathrm{w}=2 * \mathrm{pi}^{*} 50 ; \%$ frequency

$\mathrm{R}=9 ; \%$ load Resistance

$\mathrm{E}_{\mathrm{o}}=0.05$;

$\mathrm{b}=3.0$;

$\mathrm{p}=20 \mathrm{e}-6$

$\mathrm{jc}=2 \mathrm{e}+7 ; \%$ Current Density

$\mathrm{Ec}=1 \mathrm{e}-4$

$\mathrm{Tc}=108 ; \%$ Critical Temperature of the High Temp. Superconductor

$\mathrm{a}=7.5$

In $=9000 *$ sqrt (2); \% Nominal Current

thick_hts $=2 \mathrm{e}-3$; \% thickness of HTS (check this value)

wth_hts $=$ In $/(0.7 *$ jc $*$ thick_hts $) ; \%$ width of HTS

thick_ss $=4 \mathrm{e}-2 ; \%$ thickness of stainless steel

wth_ss $=2 \mathrm{e}-3 ; \%$ width of stainless steel

A = wth_hts*thick_hts; \% Area of HTS

$1=80 ; \%$ length of HTS (check this value)

$\mathrm{L} 1=0.0165 ; \%$ initial inductance

$\mathrm{h}=0.00001 ; \%$ Runge-Kutta step size

$\mathrm{I}=0 ; \%$ current at starting

$\mathrm{t}=0 ; \%$ starting time

$\mathrm{TT}=77 ; \%$ initial temperature of superconductor

NSS $=20 ; \%$ stainless steel layers

NHTSC $=40 ; \%$ HTS layers

$\mathrm{KSS}=8 ; \%$ thermal conductivity of stainless steel

KHTSC $=1 ; \%$ thermal conductivity of HTS

$\mathrm{CSS}=2.34 \mathrm{e}+6 ; \%$ specific heat capacity of stainless steel

CHTSC $=6.35 \mathrm{e}+5 ; \%$ specific heat capacity of HTS 
$\%$ Initialising temperature for all layers

for $\mathrm{j}=1:(2 * \mathrm{NSS}+\mathrm{NHTSC}+1)$

$\mathrm{T}(\mathrm{j})=\mathrm{TT}$;

end

$\%$ Layer constants

$\%$ Stainless steel

for $\mathrm{j}=1$ :NSS

$\mathrm{K}(\mathrm{j})=\mathrm{KSS} ; \%$ thermal conductivity

$\mathrm{C}(\mathrm{j})=\mathrm{CSS} ; \%$ specific heat capacity

end

$\mathrm{K}(\mathrm{NSS}+1)=0.5 *(\mathrm{KSS}+\mathrm{KHTSC}) ; \%$ thermal conductivity at interface 1

$\mathrm{C}(\mathrm{NSS}+1)=0.5 *(\mathrm{CSS}+\mathrm{CHTSC}) ; \%$ specific heat capacity at interface 1

$\%$ HTSC

for $\mathrm{j}=\mathrm{NSS}+2: \mathrm{NSS}+\mathrm{NHTSC}$

$\mathrm{K}(\mathrm{j})=\mathrm{KHTSC} ; \%$ thermal conductivity

$\mathrm{C}(\mathrm{j})=\mathrm{CHTSC} ; \%$ specific heat capacity

end

$\mathrm{K}(\mathrm{NSS}+\mathrm{NHTSC}+1)=0.5 *(\mathrm{KSS}+\mathrm{KHTSC}) ; \%$ thermal conductivity atinterface 2

$\mathrm{C}(\mathrm{NSS}+\mathrm{NHTSC}+1)=0.5 *(\mathrm{CSS}+\mathrm{CHTSC}) ; \%$ specific heat capacity atinterface 2

$\%$ Stainless steel

for $\mathrm{j}=\mathrm{NSS}+\mathrm{NHTSC}+2: 2 * \mathrm{NSS}+\mathrm{NHTSC}$

$\mathrm{K}(\mathrm{j})=\mathrm{KSS} ; \%$ thermal conductivity

$\mathrm{C}(\mathrm{j})=\mathrm{CSS} ; \%$ specific heat capacity

end

$\%$ The following part creates E vs. J look-up tables

$\mathrm{a} 1=(\log (\mathrm{Eo} / \mathrm{Ec})) /\left(\log \left((\mathrm{jc} / \mathrm{jc})^{\wedge}(1-(1 / \mathrm{b}))^{*}(\mathrm{Eo} / \mathrm{Ec})^{\wedge}(1 / \mathrm{a})\right)\right)$;

for $(\mathrm{i}=1: 50)$

jss $(\mathrm{i})=((\mathrm{i} * 0.1) * 1.0 \mathrm{e}+7)+2.0 * 1 \mathrm{e} 7$;

$\mathrm{E}(\mathrm{i})=(\mathrm{Ec})^{*}\left((\mathrm{jss}(\mathrm{i}) / \mathrm{jc})^{\wedge} \mathrm{a} 1\right)$;

end

jss1=jss(50);

$\%$ The Flux flow regime

for $(\mathrm{i}=1: 50)$

$\mathrm{jss}(50+\mathrm{i})=((\mathrm{i} * 0.05) * 1.0 \mathrm{e}+8)+\mathrm{jss} 1$;

$\mathrm{E}(50+\mathrm{i})=\left[(\mathrm{Eo})^{*}(\mathrm{Ec} / \mathrm{Eo})^{\wedge}(\mathrm{b} / \mathrm{a})\right]^{*}\left[(\mathrm{jss}(50+\mathrm{i}) / \mathrm{jc})^{\wedge} \mathrm{b}\right]$;

end

jss2=jss(100);

$\%$ The Normal conducting regime

for $(\mathrm{i}=1: 50)$

jss $(100+\mathrm{i})=((\mathrm{i} * 0.05) * 1.0 \mathrm{e}+8)+\mathrm{jss} 2$

$\mathrm{E}(100+\mathrm{i})=(\mathrm{p} * \mathrm{TT} * \mathrm{jss}(100+\mathrm{i})) / \mathrm{Tc}$;

end

$\%$ Create T vs. rho look-up tables

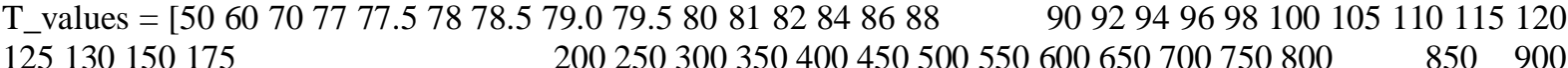

125130150175

200250300350400450500550600650700750800

950 1000];

rho_values $=(1.4 \mathrm{e}-6) *[.7 .75 .8 .91 .84 .19 .314 .519 .824 .226 .8$

27.528 .629 .730 .831 .93334 .235 .436 .638 .141 .8

666768

$6970717273747576]$;

44.547 .25053575859606162636465

$\%$ Calculate initial superconductor resistance.

rho $=$ interp1(T_values, rho_values, $\mathrm{T})$

$\mathrm{R} \_$sup $=$rho $* 1 / \mathrm{A}$;

for $\mathrm{m}=1: 10000$

Current $(\mathrm{m})=\mathrm{I}$

$\operatorname{Time}(\mathrm{m})=\mathrm{t}$;

$\mathrm{J}=\mathrm{I} / \mathrm{A}$;

if $(\mathrm{m}>4000) \%$ Close switch after two cycles.

$\mathrm{V} 1=\mathrm{V}^{*} \sin \left(\mathrm{w}^{*} \mathrm{t}\right)$;

$\%$ Current $(\mathrm{m})=\mathrm{I}$; 
$\% \operatorname{Time}(\mathrm{m})=\mathrm{t}$;

$\mathrm{E} 1=\mathrm{abs}(\mathrm{V} 1) / \mathrm{l}$

$\%$ Current density for layers

cur_den $1=0.1 * \operatorname{abs}(\mathrm{I}) /($ wth_ss*thick_ss*2*NSS $) ; \%$ Stainless Steel

cur_den $2=0.9 * \operatorname{abs}(\mathrm{I}) /($ wth_hts*thick_hts*NHTSC $) ; \%$ HTS

for $\mathrm{j}=1$ :NSS

$\mathrm{JJ}(\mathrm{j})=$ cur_den 1 ;

end

for $\mathrm{j}=\mathrm{NSS}+\mathrm{NHTSC}+2: 2 * \mathrm{NSS}+\mathrm{NHTSC}$

$\mathrm{JJ}(\mathrm{j})=$ cur_den 1 ;

end

for $\mathrm{j}=\mathrm{NSS}+2: \mathrm{NSS}+\mathrm{NHTSC}+1$

$\mathrm{JJ}(\mathrm{j})=$ cur_den 2 ;

end

$\%$ Interface values

$\mathrm{JJ}(\mathrm{NSS}+1)=0.5^{*}($ cur_den $1+$ cur_den 2$)$;

$\mathrm{JJ}(\mathrm{NSS}+\mathrm{NHTSC}+1)=0.5^{*}($ cur_den $1+$ cur_den 2$)$;

$\%$ Calculating Q

SS_layer $=$ thick_ss/NSS;

HTSC_layer $=$ thick_hts/NHTSC;

$\mathrm{Q}(1)=0$;

for $\mathrm{j}=2$ :NSS

$\mathrm{Q}(\mathrm{j})=\mathrm{JJ}(\mathrm{j}) * \mathrm{E} 1$; \% Heat input for SS layer

end

for $\mathrm{j}=\mathrm{NSS}+1: \mathrm{NSS}+\mathrm{NHTSC}$

$\mathrm{Q}(\mathrm{j})=\mathrm{JJ}(\mathrm{j}) * \mathrm{E} 1$; \% Heat input for Superconductor layer

end

for $\mathrm{j}=\mathrm{NSS}+\mathrm{NHTSC}+1: 2 * \mathrm{NSS}+\mathrm{NHTSC}$

$\mathrm{Q}(\mathrm{j})=\mathrm{JJ}(\mathrm{j}) * \mathrm{E} 1$; \% Heat input for SS layer

end

$\%$ Calculating Temperature

for $\mathrm{j}=2$ :NSS

$T(j)=T(j)+[K(j) * h *(T(j+1)-2 * T(j)+T(j-$

$1))] /\left[\left(C(j) * S S \_l a y e r * S S \_l a y e r\right)\right]+Q(j) * h / C(j)$;

if $(j=3)$

$\mathrm{TT} 1(\mathrm{~m})=\mathrm{T}(\mathrm{j})$;

end

if $(\mathrm{j}=15)$

$\mathrm{TT} 2(\mathrm{~m})=\mathrm{T}(\mathrm{j})$;

end

end

for $\mathrm{j}=\mathrm{NSS}+1: \mathrm{NSS}+\mathrm{NHTSC}$

$\mathrm{T}(\mathrm{j})=\mathrm{T}(\mathrm{j})+[\mathrm{K}(\mathrm{j}) * \mathrm{~h} *(\mathrm{~T}(\mathrm{j}+1)-2 * \mathrm{~T}(\mathrm{j})+\mathrm{T}(\mathrm{j}-1))] /\left[\left(\mathrm{C}(\mathrm{j}) * H T S C \_l a y e r * H T S C \_l a y e r\right)\right]+Q(j) * h / C(j)$ if $(\mathrm{j}=24)$

$\mathrm{TT} 3(\mathrm{~m})=\mathrm{T}(\mathrm{j})$;

end

if $(\mathrm{j}=30)$

$\mathrm{TT} 4(\mathrm{~m})=\mathrm{T}(\mathrm{j})$;

end

if $(\mathrm{j}=36)$

$\operatorname{TT} 5(\mathrm{~m})=\mathrm{T}(\mathrm{j})$;

end

end

for $\mathrm{j}=\mathrm{NSS}+\mathrm{NHTSC}+1: 2 * \mathrm{NSS}+\mathrm{NHTSC}$

$T(j)=T(j)+[K(j) * h *(T(j+1)-2 * T(j)+T(j-1))] /\left[\left(C(j) * S S \_l a y e r * S S \_l a y e r\right)\right]+Q(j) * h / C(j)$; if $(\mathrm{j}=45)$

$\mathrm{TT} 6(\mathrm{~m})=\mathrm{T}(\mathrm{j})$;

end

if $(j=56)$ 
$\mathrm{TT} 7(\mathrm{~m})=\mathrm{T}(\mathrm{j})$;

end

end

$\%$ Calculation of average temperature of HTS layer

sum = 0;

for $\mathrm{j}=\mathrm{NSS}+1: \mathrm{NSS}+\mathrm{NHTSC}+1$

$\operatorname{sum}=\operatorname{sum}+\mathrm{T}(\mathrm{j})$;

end

T_av = sum/NHTSC;

$\%$ Calculate new superconductor resistance

rho $=$ interp1(T_values, rho_values, $\mathrm{T}_{-}$av);

$\mathrm{R} \_$sup $=$rho $* 1 / \mathrm{A}$;

R_sup_values $(\mathrm{m})=\mathrm{R} \_$sup;

$\mathrm{I}=\mathrm{V} 1 / \mathrm{R} \_$sup;

$\mathrm{t}=\mathrm{t}+\mathrm{h} ; \%$ increment of time

end

if $(\mathrm{m}<=4000)$

if $\operatorname{abs}(\mathrm{J})<=$ jss 1

$\mathrm{E} 1=(\mathrm{Ec}) *\left((\operatorname{abs}(\mathrm{J}) / \mathrm{jc})^{\wedge} \mathrm{a} 1\right)$

elseif $(\operatorname{abs}(\mathrm{J})>\mathrm{jss} 1) \&(\operatorname{abs}(\mathrm{J})<\mathrm{jss} 2) ; \%$ \#ok<AND2>

$\mathrm{E} 1=\left[(\mathrm{Eo})^{*}(\mathrm{Ec} / \mathrm{Eo})^{\wedge}(\mathrm{b} / \mathrm{a})\right]^{*}\left[(\mathrm{abs}(\mathrm{J}) / \mathrm{jc})^{\wedge} \mathrm{b}\right]$;

else

$\mathrm{E} 1=\left(\mathrm{p} * \mathrm{~T}^{*} \mathrm{abs}(\mathrm{J})\right) / \mathrm{Tc}$;

end

$\mathrm{L}=\mathrm{L} 1$;

$\%$ Current density for layers

cur_den $1=0.1 * \operatorname{abs}(\mathrm{I}) /($ wth_ss*thick_ss $* 2 * \mathrm{NSS}) ; \%$ SS Layer

cur_den $2=0.9 * \operatorname{abs}(\mathrm{I}) /($ wth_hts*thick_hts*NHTSC $) ; \%$ HTS Layer

for $\mathrm{j}=1$ :NSS

$\mathrm{JJ}(\mathrm{j})=$ cur_den 1 ;

end

for $\mathrm{j}=\mathrm{NSS}+\mathrm{NHTSC}+1: 2 * \mathrm{NSS}+\mathrm{NHTSC}$

$\mathrm{JJ}(\mathrm{j})=$ cur_den 1 ;

end

for $\mathrm{j}=\mathrm{NSS}+2: \mathrm{NSS}+\mathrm{NHTSC}+1$

$\mathrm{JJ}(\mathrm{j})=$ cur_den 2 ;

end

$\%$ Interface values

$\mathrm{JJ}(\mathrm{NSS}+1)=0.5^{*}($ cur_den $1+$ cur_den 2$)$;

$\mathrm{JJ}(\mathrm{NSS}+\mathrm{NHTSC}+1)=0.5^{*}($ cur_den $1+$ cur_den 2$)$;

$\%$ Calculating Q

SS_layer $=$ thick_ss/NSS;

HTSC_layer $=$ thick_hts/NHTSC;

$\mathrm{Q}(1)=0$;

for $\mathrm{j}=2$ :NSS

$\mathrm{Q}(\mathrm{j})=\mathrm{JJ}(\mathrm{j}) * \mathrm{E} 1$; \% Heat input for SS layer

end

for $\mathrm{j}=\mathrm{NSS}+1: \mathrm{NSS}+\mathrm{NHTSC}$

$\mathrm{Q}(\mathrm{j})=\mathrm{JJ}(\mathrm{j}) * \mathrm{E} 1$; \% Heat input for SC layer

end

for $\mathrm{j}=\mathrm{NSS}+\mathrm{NHTSC}+1: 2 * \mathrm{NSS}+\mathrm{NHTSC}$

$\mathrm{Q}(\mathrm{j})=\mathrm{JJ}(\mathrm{j}) * \mathrm{E} 1$; \% Heat input for SS layer

end

$\%$ Calculating Temperature

for $\mathrm{j}=2$ :NSS

$T(j)=T(j)+[K(j) * h *(T(j+1)-2 * T(j)+T(j-$

1) $)] /\left[\left(C(j) * S S \_l a y e r * S S\right.\right.$ layer $\left.)\right]+Q(j) * h / C(j)$;

if $(j=3)$

$\mathrm{TT} 1(\mathrm{~m})=\mathrm{T}(\mathrm{j})$; 


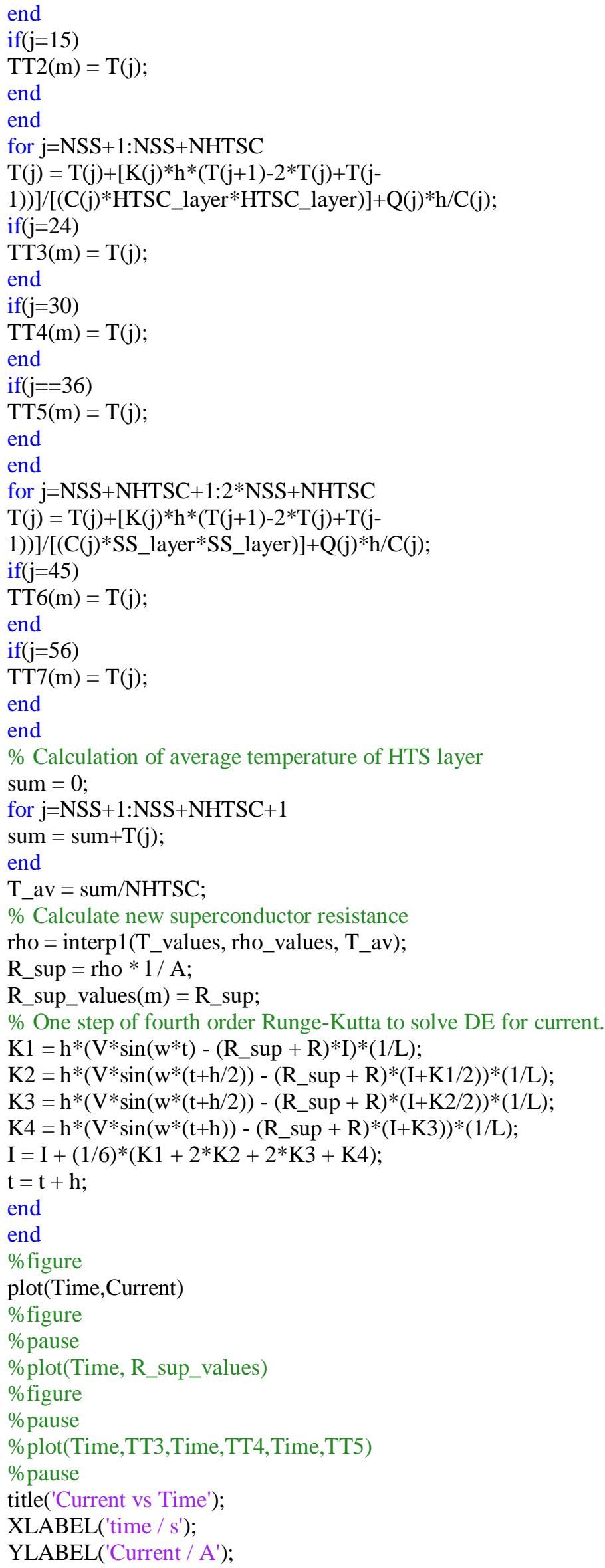




\subsection{Design Of Htsfcl Element}

As explained above, the sample used for modelling is an $110 \mathrm{kV}, 9 \mathrm{kA}$ system.

1) Current: The critical current density of the Superconductor is Jc. In order to have tolerance during normal operation or condition the current density should not exceed $\mathrm{k} \%$ of the Jc. In is the value of nominal current. In this case the $I_{p}=9000 *$ sqrt 2 is the peak current. The current Density is calculated by the dividing the current by the area it occupies $(J=I / A)$. Here the $J_{c}=I_{p} / A$ and the critical current density should not exceed $k \%$ of the $J_{c}$, so the value of the area should be calculated by $A=I_{p} /(k * J c)$. The value of critical current density $J_{c}$ is $2 \mathrm{e}+7 \mathrm{~A} / \mathrm{m}^{\wedge} 2$. Results with a different value of $\mathrm{k}$ are shown later in this chapter. The current density is dependent on the material used.

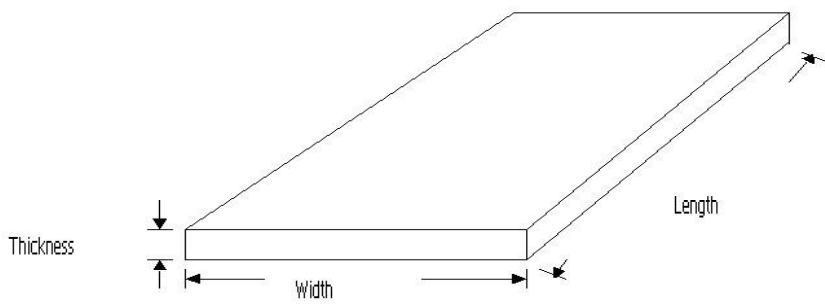

Figure 3.3 High Temperature Superconductor

\section{2) A = Thickness*Width}

Referring to the above Figure 3.3 the area is calculated. In the modeling various thicknesses are modeled such as, $0.2 \mathrm{~mm}$ and $0.9 \mathrm{~mm}$. The corresponding widths are calculated.

3) Length of the HTS (High Temperature Superconductor) wire the sample used for modelling is on an $110 \mathrm{kV}$ and $9 \mathrm{kA}$ system. Figure 3.3 shows the typical superconductor. The area of the wire is calculated by, $\mathrm{A}=$ Thickness*Width. In the modelling various thicknesses are modelled and the corresponding width is calculated. The peak voltage $\left(\mathrm{V}_{\text {peak }}\right)$ of the system is given as $110000 *$ sqrt2. This is related to the peak electric field $\left(\mathrm{E}_{\text {peak }}\right)$ and the HTSFCL length by the equation $\mathrm{V}_{\text {peak }}=\mathrm{E}_{\text {peak }} * \mathrm{HTSFCL}$ length. Various $\mathrm{E}_{\text {peak }}$ values were used in the modelling. Results with different lengths of the superconductor are shown and analysed.The value of the electric field in the three distinguishable states; zero resistance (State 1), Transition State (State 2) and normal conductance (State 3) are obtained using the following equations, which is approximated by a power law.

State 1(Superconductor or Zero resistance state)

$E(j, T)=E c^{*}(j / j c(T))^{\wedge} \alpha(T)$ where $\alpha(T)=\max \left[\beta, \alpha^{\prime}(T)\right]$, with $\alpha^{\prime}(T)=\log \left(E_{0} / E_{c}\right) / \log \left[\left(j_{c}(77 K) / j c(T)\right)^{\wedge}(1-\right.$ $\left.1 / \beta)^{*}(\mathrm{Eo} / \mathrm{Ec})^{\wedge} 1 / \alpha(77 \mathrm{~K})\right]$ where $j_{\mathrm{c}}$ is the critical current density and $\mathrm{E}_{\mathrm{c}}=1 \mu \mathrm{V} / \mathrm{cm}, \mathrm{E}_{\mathrm{o}}, \alpha, \beta$ at $77 \mathrm{k}$ depends on the material processing conditions and is within the following ranges

$0.1 \leq \mathrm{E}_{\mathrm{o}} \leq 10 \mathrm{mV} / \mathrm{cm}$,

$5 \leq \alpha \leq 15$,

$2 \leq \beta \leq 4$.

State 2 (Transition state or flux flow state)

$E(j, T)=E o^{*}(E c / E o)^{\wedge} \beta / \alpha(77 K) * j_{c}(77 K) / j c(T) *(j / j c(77 K))^{\wedge} \beta$

State 3 normal state or high resistance state

$\mathrm{E}(\mathrm{j}, \mathrm{T})=\mathrm{p}(\mathrm{Tc}) * \mathrm{~T} / \mathrm{Tc} * \mathrm{j}$

\subsection{RESULTS AND ANALYSIS}

\subsubsection{Normal Operation}

During steady state or normal operation the switch $\mathrm{S}$ is open (Figure3.1). The flow of the current is shown in Figure 3.4. The start current is zero and start time, ( $\mathrm{t}$ ) is zero. From Figure 3.4 it can be seen that the current during normal operation is pure sinusoidal. The nominal current during normal operation is $9000 *$ sqrt 2 A. Figure 3.5 shows the temperature-time graph during normal operation. It can be seen that temperature remains constant at $77 \mathrm{~K}$ as the superconductor is cooled by liquid Nitrogen. Due to the constant temperature of the superconductor, the HTSFCL remains in the superconductor state or zero resistance state. 


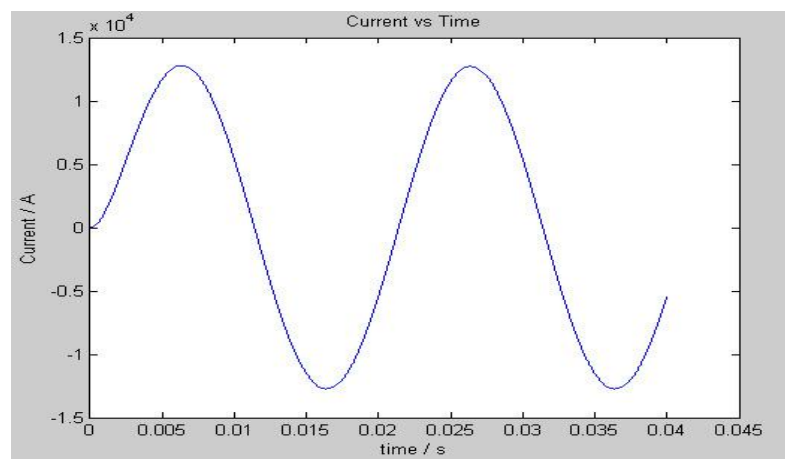

Figure 3.4 Current Waveform during normal operation

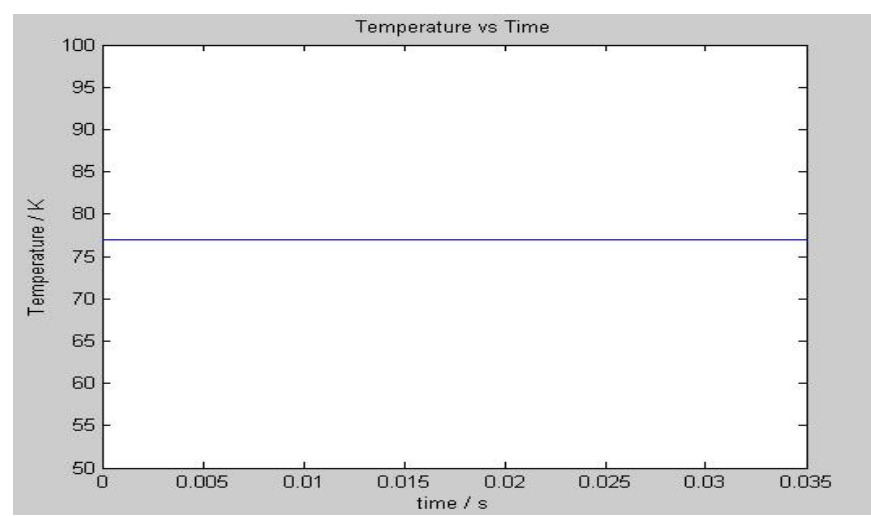

Figure 3.5 Temperature vs. Time

The voltage drop across the HTSFCL during normal operation is very low (approx. zero) as it offers zero resistance in normal operation. The losses during normal operation are much less and therefore are neglected

\subsection{Operation During Fault}

In order to see operation of the HTSFCL during fault, the Switch S in Figure 4.5 is closed after two cycles. The Figure 3.6 shows the circuit during fault.

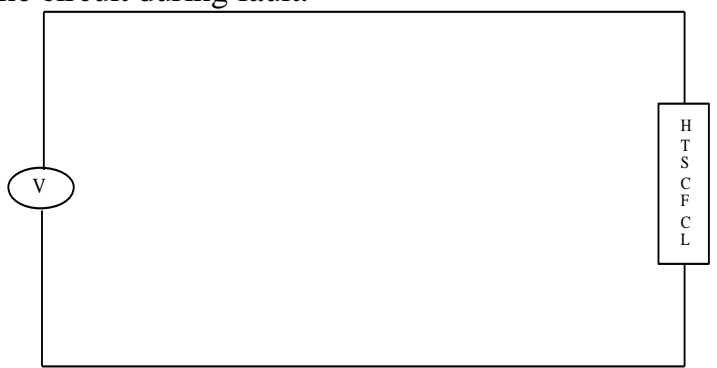

Figure 3.6 Circuit under fault conditions

During fault the whole supply voltage appears across the HTSFCL. There is large voltage drop across the HTSFCL. Figure 3.7 shows the current waveform during fault. The switch S in Figure 3.1 is closed after two cycles (at $0.04 \mathrm{esc}$ ). 


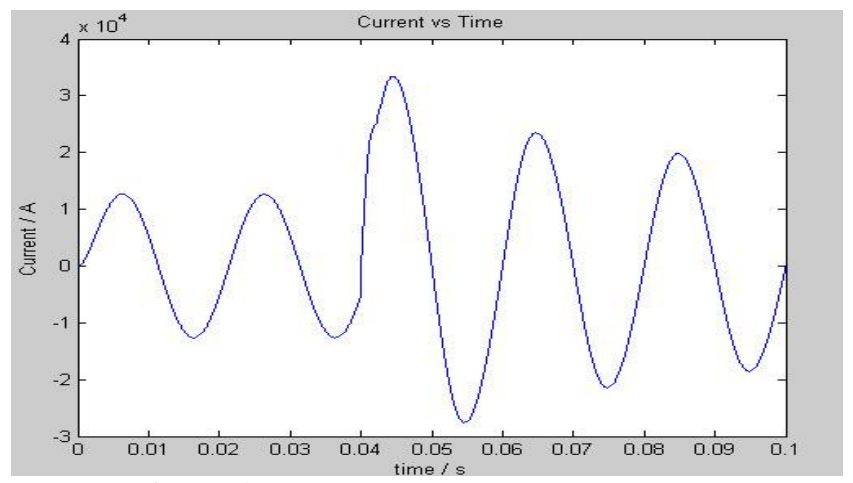

Figure 3.7 Current waveform during fault

From Figure 3.7 it can be seen that the current rises to a large value at 0.04 seconds, when switch $\mathrm{S}$ is closed. The maximum fault current becomes more than $31 \mathrm{KA}$, which is more than three times the nominal value of the current. From Figure 4.11, it can be seen that the HTSFCL takes a fraction of a second to limit the fault current. Figure 3.8 show the change in the resistance of the superconductor during fault.

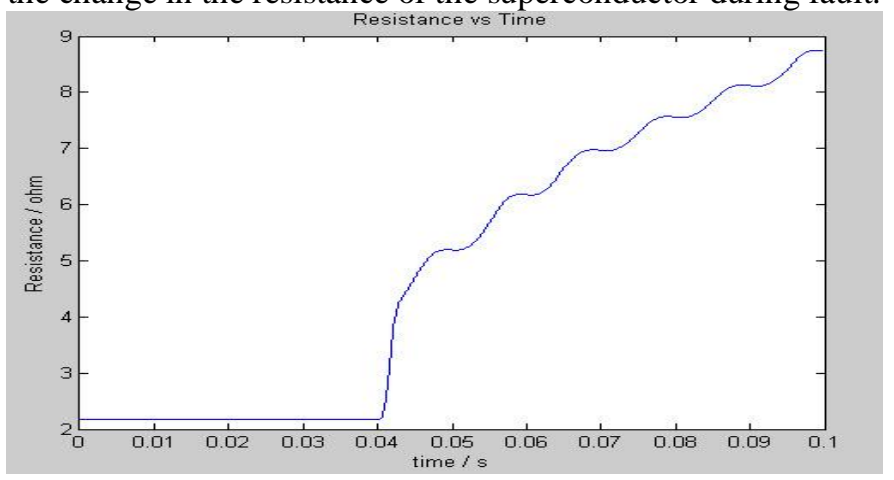

Figure 3.8 Variation in resistance with time

Actually the exact value of the resistance of the superconductor cannot be known but from Figure 3.9 it can be shown that there will be sharp increase in the resistance of the HTFSFCL during fault. This sharp increase in the resistance of the HTSFCL limits the fault current. As the resistance increases, the HTSFCL comes out of superconductor state, or zero resistance state, and operates in normal conductance state, offering very high resistance to the fault current. Due to the high resistance of the superconductor during fault a very large amount of heat is produced which may damage the superconductor element in the HTSFCL. In order to avoid damage of the superconductor element due to heat the stainless steel around the superconductor takes the heat from superconductor and dissipates it. Figure 3.9 shows the rise in temperature of the superconductor layers and the surrounding stainless steel layers. The critical temperature (Tc) is $108 \mathrm{~K}$ in this case. When the temperature becomes greater than the critical temperature of the superconductor it switches to a high resistance state, due to which the fault current is limited to a low value, thus saving the equipment installed in the power grid or circuit.

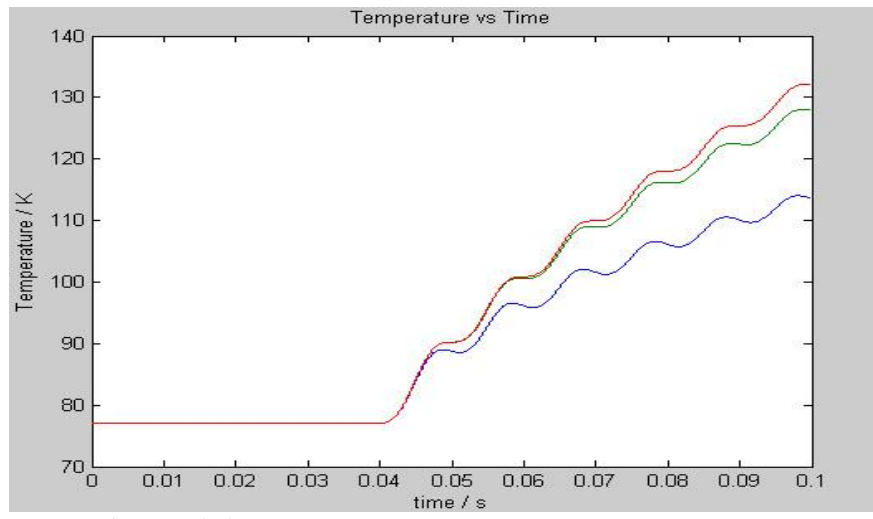

Figure 3.9 Change in temperature of the HTSFCL

The transition state of the superconductor from superconducting state to normal state or high resistance 
state depends on heating of the superconductor. If the fault current is very high superconductor element heated up very fast. This causes the temperature of the superconductor to become more than the critical temperature so it operates in a high resistance state. Due to fast heating of the superconductor element, it very quickly switches to normal state or high resistance state. In slow heating the transition time is longer as compared to fast heating of the superconductor. During fault a large amount of fault current flows through the superconductor, resulting in heating of the superconductor element and which may result in formation of the hot spot, thus damages the superconductor. It is desirable that the heat generated in the superconductor during fault should be absorbed by the stainless steel layers around it, thus protecting the superconductor from damage. The behaviour of the HTSFCL is largely determined by its length and the type of material used. The shorter conductor length with fast heating no doubt saves expense on conductor material but there will be a large electric field distributed over the superconductor resulting in overheating. In a few hundred microseconds the HTSFCL enters the normal conductance zone or high resistance state. In this case there will be quite slow recovery of the superconducting state. More over there will be severe over voltages along with current reduction, caused by the rapid transition to normal conduction state. In order to reduce these overvoltages, a normal resistor or reactor should be used in parallel to the HTSFCL. Below some results are shown for changing the length of the superconductor. Below some results are shown for changing the length of the superconductor.

Table 3.1

Fault Current \& Temperature corresponding to different Length of Superconductor at $\mathrm{k}=0.8$, thickness $=.002 \mathrm{~m}$ and Specific heat capacity $=6.35 \mathrm{e}+5(\mathrm{~kJ} \mathrm{~kg}-1 \mathrm{~K}-1)$

\begin{tabular}{|l|l|l|l|l|}
\hline $\begin{array}{l}\text { Length } \\
\mathrm{E}(\mathrm{m})\end{array}$ & $(\mathrm{v} / \mathrm{m})$ & $\begin{array}{l}\text { Fault Current } \\
(\mathrm{A})\end{array}$ & $\begin{array}{l}\text { Fault Current after I } \\
\text { and 2 cycles }(\mathrm{A})\end{array}$ & $\begin{array}{l}\text { Temp } \\
(\mathrm{K})\end{array}$ \\
\hline 70 & 2222 & 40572 & 25976,22019 & 151 \\
\hline 80 & 1944 & 36700 & 24700,20350 & 137 \\
\hline 100 & 1555 & 30701 & 22718,19130 & 120 \\
\hline 120 & 1296 & 26298 & 21041,17703 & 113 \\
\hline
\end{tabular}

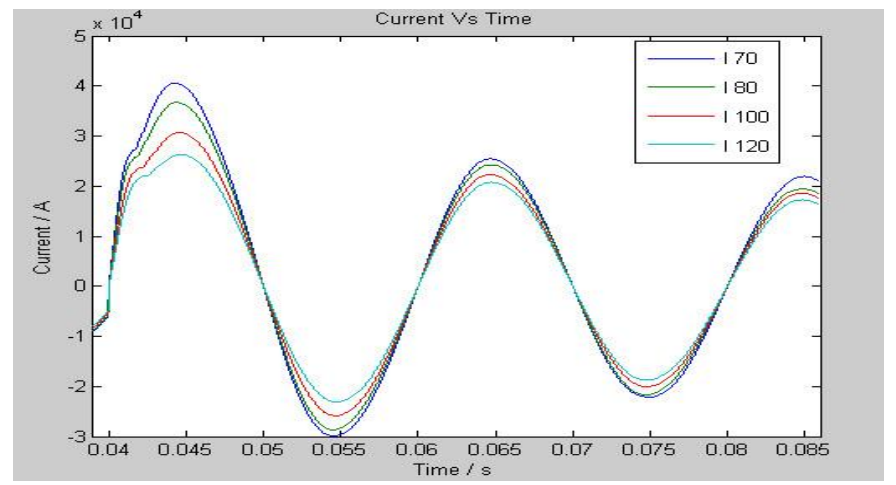

Figure 3.10 (a)

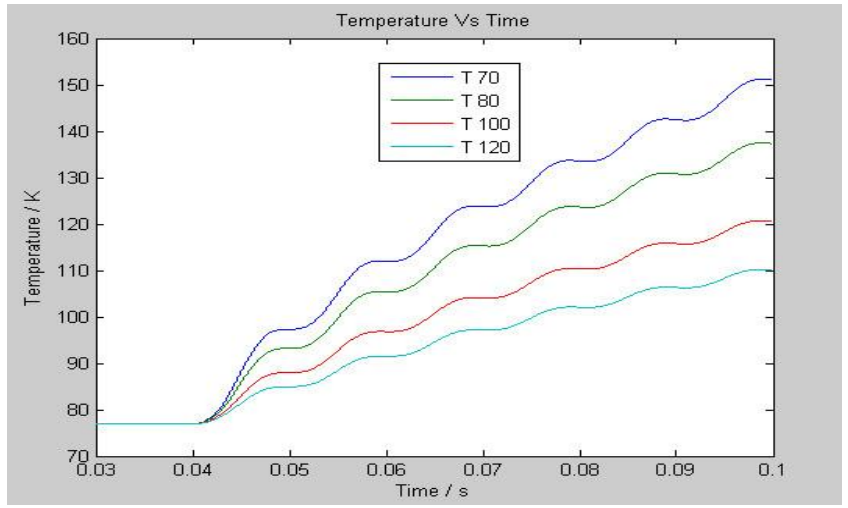

Figure 3.10 (b)

Figure 3.10 (a) Fault Current and (b) Temperature corresponding to different length of the superconductor at thickness of $0.002 \mathrm{~m}(\mathrm{k}=0.8)$

The above table 3.1 shows the value of fault current, electrical field and temperature corresponding to different values of length. The results shown in Figure 3.10 and table 3.1 are of superconductors for thickness equal to $0.002 \mathrm{~m}$ and $\mathrm{k}=0.8$. From table 3.1 it can be observed that with a smaller length of the superconductor a 
strong electric field is developed and also a large fault current flow in the model. As explained earlier with a short length of the superconductor a large amount of heat is produced and which may damage the superconductor. In Figure 3.10 (b) the blue line (T 70) shows the temperature of a superconductor at length $70 \mathrm{~m}$, it can be observed that as the length of the conductor is increased, there is decrease in the electrical field which results in decrease in the fault current and also temperature of the superconductor. Now we will change the thickness of the superconductor and will see its effect on the operation of the HTSFCL.

Table 3.2

Fault Current \& Temperature corresponding to different Length of Superconductor at $\mathrm{k}=0.8$, thickness of $.009 \mathrm{~m}$ and specific heat capacity $=6.35 \mathrm{e}+5(\mathrm{~kJ} \mathrm{~kg}-1 \mathrm{~K}-1)$

\begin{tabular}{|l|l|l|l|l|}
\hline $\begin{array}{l}\text { Length } \\
\mathrm{E}(\mathrm{m})\end{array}$ & $(\mathrm{v} / \mathrm{m})$ & $\begin{array}{l}\text { Fault } \\
\text { Current }(\mathrm{A})\end{array}$ & $\begin{array}{l}\text { Fault Current after I } \\
\text { and 2 cycles }(\mathrm{A})\end{array}$ & Temp (K) \\
\hline 70 & 2222 & 40588 & 25446,21935 & 157 \\
\hline 80 & 1944 & 36711 & 24267,19137 & 142 \\
\hline 100 & 1555 & 30706 & 22279,18581 & 124 \\
\hline 120 & 1296 & 26301 & 20762,17256 & 112 \\
\hline
\end{tabular}

Table 3.2 shows the values of the fault current and temperature when the thickness of the superconductor is increased to $0.009 \mathrm{~m}$. If we compare the table 3.2 with table 3.1 it can be seen that the rise in temperature of same length is greater when the thickness of the superconductor is increased. The heat produced during fault is dissipated much faster if the thickness is less. Figure 3.11(a) shows the current waveforms corresponding to different length of the superconductor when the thickness is $0.009 \mathrm{~m}$. It is observed that the fault current is a little bit more in Figure 3.11(a) as compared with Figure 3.10(a). Figure 3.11(b) shows the change in the temperature of the superconductor corresponding to the change in length of the superconductor. The thickness of the conductor in this case is $0.009 \mathrm{~m}$, where it is $0.002 \mathrm{~m}$ in Figure 3.10 (b). It can be seen that with an increase in the thickness of the superconductor the temperature also increases more than when the thickness is $0.002 \mathrm{~m}$. In Figures 3.10 (a) and 3.11(a) the blue line (I 70) is the current corresponding to $70 \mathrm{~m}$ length of the Superconductor and the red line is the fault current corresponding to superconductor length $100 \mathrm{~m}$. It can be observed also that as the length is increased the fault current is reduced closer to its nominal value

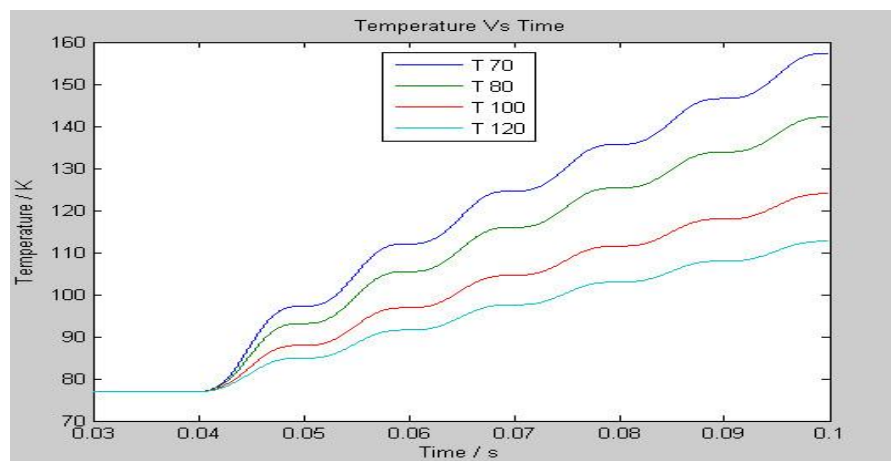

Figure 3.11(a)

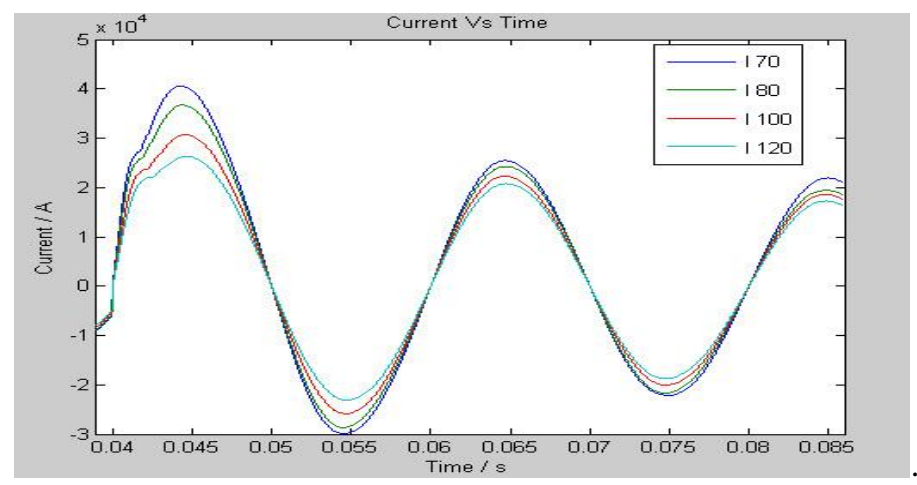

Figure 3.11 (b)

Figure 3.11(a) Fault Current (b) Temperature corresponding to different lengths and at thickness of $0.009 \mathrm{~m}$ of the superconductor. $(\mathrm{k}=0.8)$. 
Similarly in Figures 3.10(b) and 3.11(b), the blue line shows the rise in the temperature of the superconductor of length $70 \mathrm{~m}$ during fault and red line shows the temperature rise in the superconductor corresponding to length of 100m. From the above Figures 3.10(b) and Figure 3.11(b). It can be seen that as the length of the superconductor is increased the temperature is decreased. As explained earlier too short length of the superconductor is not suitable as it will damage the superconductor element in the HTSFCL due to large amount of heat is produced during fault. If very long superconductor is used, the amount of electric field to which it is exposed is very less and as the field varies in direct proportion with the voltage and inversely with the conductor length, which results in the critical current density to exceed only slightly and will stay within the outer boundary of the transition region. The conductor warms up slowly due to its length, causing high AC losses, which will result in heavier demand of the cooling system. Also due to the length of the conductor, the temperature is constant and the limiter does not heat up, so the device can be brought back into operation as soon as the breaker is closed. For a long conductor a large amount of superconductor is needed, results in additional cost. The other drawback of using a long conductor is that it takes a long time to return from its normal state to its superconducting state. If a superconductor of intermediate length is used the electric field during fault will be high but still less than the electrical field imposed on a conductor of a very short length. In this case the current density rises to greater value during fault than it rises to in the case of a long conductor, although remains inside the transition region. The power dissipated will be higher in this case than in the case of a longer conductor, so the conductor will heat up and after a few tens of milliseconds it will pass the outer transition boundary and enter the normal conducting region. As explained earlier, to keep a tolerance during normal operation the current density $\mathrm{J}$ should not exceed $\mathrm{k} \%$ of Jc. The value of $\mathrm{k}$ was 0.8 for the above results, now we will change the value of $\mathrm{k}$ to 0.7 or $70 \%$ of Jc. The results for $\mathrm{k}=0.7$ are reported and the change in the fault current and temperature is observed.

\section{Conclusions}

From the MATLAB simulation it is clear that the HTSFCLs are an effective technique for limiting the potentially damaging effects of the fault current on the equipment installed in the power systems. HTSFCLs are the most common uses of the superconductors and they are increasingly being used in electrical applications. As the MATLAB simulation uses simple circuit, the general principles are applicable in real world circuits. Results with different lengths of the superconductor are reported. It is observed that a superconductor of intermediate length is used. The length depends on the level of fault current to be interrupted. In order to apply some tolerance $\mathrm{k}=0.8$ is used. The superconductor is cooled by liquid Nitrogen; as good and reliable cooling system is required in order to have efficient operation of the HTSFCL.Thickness of $0.002 \mathrm{~m}$ is used because the temperature rise is less and heat from the superconductor can be easily removed during fault. The Superconductor element is surrounded by stainless steel in order to remove heat from the superconductor element during fault and avoid any damage to the superconductor. The detail of the MATLAB script used is shown above.

\section{References}

[1] Schmitt. H, CIGRE," Fault current limiters report on the activities of CIGRE WG A3.16", Power Engineering Society General Meeting, 2006. IEEE, 18-22 June 2006, pp.5

[2] M.M.A.Salama, R.Sarfi and A.Y.Chikhani," Computer Controlled Fault Current Limiter (CCFCL)", Proceedings on Electric Machines and Power Systems, Vol. 24, 1996, pp 653-667

[3] E.F.King, A.Y.Chikhani, R.Hackman and M.M.A.Salama,"A Microprocessor Controlled Variable Impedance Adaptive Fault Current Limiter", IEEE Transactions on Power Delivery, Vol. 5, No.4, Nov. 1990, pp 1830 -1837.

[4] E.S.Ibrahim,"Electromagnetic Fault Current Limiter", Electric Power System Research, Vol. 42, 1997, pp. 189-194.

[5] R.A Dougal,"Current-Limiting Thermistors for High-Power Application", IEEE Transaction on Power Electronics, Vol.11, No.2, March 1996, pp.304-310.

[6] I.Lee, R.Carberry, W.Knauer, B.A.Renz and S.H.Horowitz,”An Ultrafast Fault Sensor for a Fault Current Limiting Device”, IEEE Transaction on Power Apparatus and Systems, Vol. PAS-98, No.3, April 1992, pp.507-515.

[7] T.F.Godart, A.F.Imce, J.C.Mclver and E.A.Chebli,'Feasibility of Thyristor Controlled Series Capacitor for Distribution Substation Enhancements", IEEE Transactions on Power Delivery, Vol. 10, No. 1, January 1995, pp.203-209.

8] M.Samii,'Inrush Current Limiters", PCIM, Oct.1998, pp94

[9] S.C.Mukhopadhyay, M.Iwahara, S.Yamada and F.P.Dawson," Analysis, Design and Experimental Results for A Passive Current Limiting Device", IEE Proceedings on Electric Power Applications, U.K., IEE, 146, May 1999, 3, pp. $309-316$.

[10] M.Iwahara, S.C.Mukhopadhyay, N.Fujiwara and S.Yamada," Development of Passive Fault Current Limiter in Parallel Biasing Mode", Proc. on IEEE Intermag conference, Kiangsu, Korea, May 18-21, 1999, AS-09.

[11] N.Ishihara, S.C.Mukhopadhyay, M.Iwahara and S.Yamada, "Dependency of the Core Characterization on a Passive Fault Current Limiter using a Permanent Magnet, Journal of the Magnetics Society of Japan, 22, April 1998, 4-2, pp. 725-728 